\section{Questión}

Periodismo / Comunicación ISSN 1669-6581
- Av. $44 \mathrm{~N}^{\circ} 676,1^{\circ}$ piso

CP 1900 - La Plata - Argentina

www.perio.unlp.edu.ar/question

\title{
ENTORNOS VIRTUALES EN TIEMPOS DE CORONAVIRUS
}

\section{VIRTUAL ENVIRONMENTS IN CORONAVIRUS TIMES}

Egresada de la Facultad de Periodismo y Comunicación Social (UNLP). Profesora Adjunta de la cátedra Comunicación y Medios de la citada unidad académica. Integrante de los equipos de investigación de los siguientes proyectos: "Drogadicción, Medios y Cultura, un intento de articulación" (1995-1997), "La construcción de lo político en jóvenes, en relación a la televisión" (1997-1999), "La relación de los jóvenes con la política" (1999-2001), "Ciudad/Comunicación: prácticas sociales del uso y percepción de la ciudad de La Plata" (2002-2003), "Usos socio-políticos de las Tecnologías de Información y Comunicación (TIC) de la Sociedad de la Información (SI) aplicadas en los procesos políticos en ámbitos locales. Estudios de casos en la Región Capital: Municipios de La Plata, Berisso y Ensenada" (2004-2005).

Docente de las extensiones universitarias de Las Flores, Lincoln, Partido de la Costa y Monte Caseros. Subjefa de

Prensa y Difusión del Centro Provincial de las Artes Teatro Argentino. Coordinadora de Premios a Comunicadores y Medios Bonaerenses, otorgados por el Consejo Profesional de Ciencias Económicas de la Provincia de Buenos Aires.

Las TIC son mi objeto de estudio desde hace años, ya sea desde la investigación, desde la docencia, o desde los distintos espacios de producción que nos brinda la vida académica.

Durante la formación de posgrado focalicé mi producción en la educación a distancia, específicamente en la capacitación en entornos virtuales para docentes, a través de políticas públicas implementadas por el Estado bonaerense durante el Bicentenario de la Revolución de Mayo.

Ese trabajo me permitió confirmar, ya por entonces, (año 2010) la importancia de las nuevas tecnologías en los procesos de enseñanza/aprendizaje. Algo absolutamente predecible, pero que necesitaba testificar a través del relato de quienes intervinieron en esa práctica educativa 
en el ejercicio de sus diferentes roles (directivos, coordinadores, tutores y docentes cursantes). Estudiar los procesos comunicacionales que se gestaron en aquel momento entre esos actores sociales en el marco de la experiencia de formación continua me permitió vislumbrar un incipiente sendero educativo- mediado por las nuevas tecnologías digitales- del cual no se volvería atrás.

No es este el espacio para detenerme en esa producción, pero sí el escenario del cual partir para reconstruir el objeto de estudio (en construcción constante) que siempre consideré dinámico, pero que jamás imaginé tendría semejante protagonismo en la coyuntura actual. No sólo las TIC en relación a la Educación, sino también la extensión de éstas a cada una de nuestras prácticas cotidianas y laborales, desde ventas online hasta videoconferencias $u$ operaciones bancarias. No porque antes no existieran sino por el poder que simbolizan en tanto opción posible para seguir viviendo (o sobreviviendo) sin salir de casa. Un virus globalizado, surgido o inventado, en otro lado del mundo, en pleno siglo XXI, nos amenaza... y ahí están ellas, las TIC para salvarnos... una vez más emerge la fantasía (o ya no tanto) redentora de la comunicación. El mundo se paraliza y ellas se activan, reactivan y potencian para garantizar nuestra existencia a través de mediaciones tecnológicas.

¿Qué diría hoy Marshall McLuhan sobre esta aldea global (1) ? o desde otro horizonte, ¿qué pensaría Michel Foucault, sobre Vigilar y castigar (2) en el mundo actual? Preguntas, siempre preguntas, respuestas que llegan después o a destiempo, propias del devenir dialéctico que nos permite pensar la comunicación siempre en movimiento.

Retomo en estas líneas aquella experiencia de capacitación virtual destinada a docentes de la provincia, en la década pasada, reviso bibliografía y me reencuentro con un texto publicado con el respaldo de la Organización de Estados Iberoamericanos (OEI), bajo el lema Metas educativas 2021, la Educación que queremos para la generación de los Bicentenarios. Se trata de una producción colectiva, coordinada por Roberto Carneiro, Juan Carlos Toscano y Tamara Díaz (2009) en la que los autores focalizan su mirada sobre los desafíos de las TIC para el cambio educativo. La publicación se realizó en el marco de la celebración de los bicentenarios de las independencias de la región. Fue el contexto pertinente para que los respectivos ministros de Educación de los países se manifestaran de manera unánime a favor de ejecutar esa acción colectiva. 
A un año de que se cumplan o no aquellas Metas, nunca imaginé que la temática basada en aulas virtuales tendría el sentido actual, ante estos Incidentes.

Entre los desafíos que se planteaban hace 10 años, se encontraban: el diseño, mantenimiento y gestión de la infraestructura tecnológica, el reto centrado en la competencia docente y la provisión de recursos y contenidos digitales.

Pasó el tiempo y los desafíos pre-existen, existen y se reinventan ante la impronta de vivir en tiempos de Coronavirus. La lógica de los medios sigue vigente, no se desplaza, se potencia, y las TIC son protagonistas en el escenario actual de la Sociedad del Conocimiento.

A 10 años de aquellas premisas mucho se trabajó en este campo para gestar el cambio educativo -aún sin saber el futuro (presente actual) - que nos esperaba en tanto ciudadanos del mundo. Con la excepción del período 2015-2019 por las razones ya conocidas, la Educación fue tema primordial para las políticas de Estado a partir del año 2003. Basta con repasar el espíritu rector de las leyes de Financiamiento Educativo №26075/05, de Educación Nacional № 26.606/06, y su correlato con la Ley Provincial de Educación №13.688/07, más las normativas que de ellas emanaron. Su vigencia nos permite retomar y reivindicar a la Educación como un bien social.

Múltiples y diversos programas se ejecutaron en Nación y Provincia relacionados con el uso y apropiación de las TIC, tanto en sus aspectos vinculados con el equipamiento como en los contenidos curriculares. En ese sentido, puedo mencionar, entre otras, iniciativas PIIE, PROMSE, FOPIIE, EQUIPAR, PROMEDU y PROMER, destinadas a escuelas rurales, urbanas, técnicas y a Institutos Superiores. Fueron acciones complementadas por el reconocido programa CONECTAR-IGUALDAD; mientras que en la provincia de Buenos Aires se lanzó el PROGRAMA DE ALFABETIZACIÓN DIGITAL.

Sin dudas, en estos últimos años la comunidad educativa se afianzó en la formación a distancia y en el uso y apropiación de las TIC, en tanto mandato de época ineludible. Ya lo había anticipado Jesús Martín-Barbero (1987) en su obra cumbre De los medios a las mediaciones cuando nos decía que las sociedades latinoamericanas debían informatizarse o morirían. Acá estamos informatizamos, por instinto de sobrevivencia, aferrados a la dinámica del mundo actual, para no quedar fuera del sistema. 
Todo este proceso previo de ejercitación digital, con aspectos positivos y negativos, confluyen en el paradigma de la convergencia, que hoy nos conecta, a través de múltiples dispositivos, en nuestra condición de globalizados.

Los Incidentes actuales nos convocan al uso intensivo de la web y redes sociales, uso que nos atraviesa en lo personal y en lo laboral. Liberados y vigilados, en la intimidad del hogar y en la exposición virtual, dejamos huellas de nuestra presencia a través de un clic en el mundo actual. Ahora más que nunca, entre lo ideal y lo real media lo virtual, las instituciones de la Educación lo saben claramente. Por eso, más allá de las Metas de los Estados y sus políticas públicas en pos del cambio educativo en la Sociedad del Conocimiento, hoy prevalece 10 real y esto implica que hay que seguir adelante con las obligaciones (en todos sus formatos). De allí el protagonismo de lo virtual, es justamente su mediación lo que hace posible nuestra existencia, en tanto sobrevivientes, en tiempos de pandemia.

Este nuevo escenario nos convoca a cumplir nuestros roles, sin medir tiempos ni distancias. En ese sentido, y concretamente en el ámbito educativo, tanto en Nación como en Provincia, se activaron plataformas para dar continuidad al proceso de enseñanza/aprendizaje.

Reviso algunas de ellas, en un recorrido apresurado, por el mundo virtual.

$>\quad$ Seguimos educando, a través del portal Educ.Ar del Ministerio de Educación de la Nación. El programa incluye diferentes propuestas a fin de estimular el acceso a contenidos educativos en las circunstancias actuales hasta tanto se retome el normal funcionamiento de las clases, destinadas a docentes y directivos, estudiantes y familias.

Se trata de una propuesta de acompañamiento a las iniciativas de jurisdicciones, escuelas y educadores. Se articulan contenidos de TV, cuadernillos y materiales digitales. Para los y las estudiantes se pone a disposición una colección de materiales y recursos educativos digitales organizados por nivel educativo y área temática; y para las familias, ideas que facilitan el acceso a contenidos educativos y bienes culturales.

$>\quad$ Apoyo a la Educación a Distancia para Facultades y Colegios en el contexto de la pandemia de COVID-19 (PAED), por medio de su web, la UNLP, puso en marcha un programa especial, a través de la Secretaría Académica, ejecutado por la Dirección General de Educación a Distancia y Tecnologías. Tiene por fin que los docentes puedan dar sus clases de modo virtual y garantizar, el acceso de contenidos educativos a los y las estudiantes, sosteniendo así la continuidad del desarrollo de las cursadas. Con esta iniciativa la Universidad 
apunta a que la comunidad educativa pueda implementar mecanismos de comunicación en línea, a través de aulas virtuales de plataformas propias de cada unidad académica o en el entorno AulasWeb que ofrece la Presidencia de la UNLP, sumadas a herramientas de uso libre disponibles hoy en la web para armar teleconferencias.

En ese sentido, nuestra Facultad, a través del sitio https: //perio.unlp.edu.ar/adistancia/, diseñado por la Secretaría de Producción y Vinculación Tecnológica, junto con la iniciativa \#PerioEnCasa, fija acciones educativas virtuales, con el fin de acompañar al estudiantado y garantizar la continuidad de los procesos de aprendizajes.

La UNLP reforzó, además, el servicio de asesoramiento para facultades, colegios, docentes y cátedras que necesitan formación, asistencia o capacitación para las tareas de enseñanza a distancia, a través del programa online Webinar del ciclo Encuentros de Asesorías en línea para educación a distancia, al cual se accede por el canal de videos de Youtube de la Dirección General de Educación a Distancia. Siguen vigentes, hoy más que nunca, las ofertas de carreras y cursos de posgrado a distancia, Educación Continua, Ingreso a Distancia y la Escuela Virtual Internacional CAVILA (Asociación de Universidades Latinoamericanas).

$>\quad$ Continuemos estudiando, es la plataforma que lanzó el Gobierno de la Provincia de Buenos Aires, a través del sitio https://continuemosestudiando.abc.gob.ar desarrollado por la Dirección de Tecnología Educativa, dependiente de la Subsecretaría de Educación de la Dirección General de Cultura y Educación (DGCyE). El objetivo es que los y las estudiantes puedan realizar sus actividades a distancia, en forma autónoma y/o con el acompañamiento de adultos/as de su entorno. En ella se encuentran materiales, recursos y propuestas de actividades educativas organizadas por las direcciones de los distintos niveles y modalidades del sistema educativo provincial para proseguir con sus respectivos aprendizajes.

> Formación Docente a Distancia, es una nueva instancia formativa destinada a directivos y docentes que aborda la continuidad pedagógica, mediante el portal abc.gov.ar. El pasado 23 de abril, la DGCyE abrió la inscripción para que la comunidad educativa bonaerense pueda abordar estrategias y herramientas con el propósito de seguir haciendo escuela. El programa comprende, en esta instancia, dos cursos: uno para equipos directivos y otro para docentes de todos los niveles y modalidades, a los que se suma una mesa de apoyo tecnológico. 
Tras este breve y apresurado repaso de iniciativas pasadas y de las abruptamente vigentes, relacionadas con la cultura digital en prácticas pedagógicas, concluyo una vez más que la presencia del Estado es irremplazable para contener y acompañar a sus ciudadanos.

Así nos encuentra esta década, globalizados por el miedo, pero no paralizados. Afortunadamente hace diez años, representantes de la Educación de los países de la región sentaron las bases del cambio educativo para la Generación del Bicentenario de la Revolución de Mayo.

Ya no es prioritario saber si se cumplieron aquellos ideales, alcanza con su gestación y acciones consecuentes. Lo importante es comprender que en el mundo real, lo virtual se torna esencial, para dar continuidad a procesos personales y laborales. Especialmente, en el campo educativo, el que nos forma y nos asigna un lugar en la Sociedad del Conocimiento, más allá de este inesperado aislamiento, tras el cual ya nada será igual y en el que seguramente emergerán nuevos saberes.

Notas.

(1). El concepto fue utilizado por Marshall McLuhan en el título de su libro Guerra y paz en la Aldea Global (1968).

(2) Vigilar y castigar. Nacimiento de la prisión, uno de los libros más reconocidos de Michel Foucault (1975).

Bibliografía

Martín-Barbero, Jesús (1987). De los medios a las mediaciones. Comunicación, cultura y hegemonía. Barcelona, España: Editorial Gustavo Gili S.A.

Carneiro, R, Toscano, J. C. y Díaz, T (Coordinadores). (2009). Los desafíos de las TIC para el cambio educativo. Metas educativas 2021. Madrid, España: Editado por la Organización de Estados Iberoamericanos para la Educación, la Ciencia y la Cultura (OEI) en colaboración con la Fundación Santillana.

Sitios.

http://www.entornosvirtuales.unlp.edu.ar/

https://unlp.edu.ar/educacionadistancia 
https://aulasweb.ead.unlp.edu.ar/

http://blogs.unlp.edu.ar/

https://perio.unlp.edu.ar/adistancia/

https://perio.unlp.edu.ar/perioencasa

https://continuemosestudiando.abc.gob.ar

http://www.abc.gov.ar/nuevo-programa-de-formacion-docente-a-distancia 